\title{
Forest Fires in Relation to Soil Fertility
}

\section{By Prof. F. P. Worley, Auckland University College, New Zealand}

W HEN the early colonists arrived in New 7.ealand, the greater part of the present cultivated land of the North Island and much of that of the South Island were covered with dense forests, which have since been removed by burning, the general practice being to remove millable timber, fell the remainder, burn out as completely as possible and sow with grass. Much of the forest was, however, burned without felling, sometimes by accident but often intentionally.

Although large areas of native forest still remain, the bush in the South Island is largely confined to mountainous regions. In the North Island, although the greater part of the remaining bush is on mountain ranges, there is still a large area of bush land that will gradually be brought into cultivation. The method of forest removal is not far removed from the primitive methods employed by some African native tribes.

Although it may be conceded that burning is the only practicable method of bringing bush land into cultivation, far too little consideration appears to have been given to the influence of forests on soil fertility and to the possible damage to the soil by the methods of burning employed. It is very obvious in numerous cases that areas formerly covered by luxuriant bush frequently have surprisingly low fertility. It has only to be recalled that the poor 'gum lands' of the North Auckland peninsula were once covered by dense kauri forests full of rich undergrowth. In other parts of the country, hillsides formerly covered by good bush, such, for example, as the coastal districts north of Wellington, have a fertility sadly below that to be expected from the luxuriance of the former bush.

It is necessary to inquire whether this apparent deterioration of fertility may be due to the method of forest removal and, for this purpose, consideration must be given to certain aspects of the part played by the forest in bringing virgin rocky land into a condition of fertility. The process can be observed on the volcanic island of Rangitoto at Auckland, where a formerly barren island of rough basalt is in process of being converted by the bush into rich, fertile land. It is not known how many hundreds of years it has taken for the island to reach its present degree of fertility, or how long it will be before the rocks are covered with fertile soil, but the process of humus formation is plainly obvious. What is not obvious, however, is the process of bringing to the surface and making available for plant growth the mineral constituents of the rocks.

The only artificial fertilisers intentionally applied to the land for agricultural purposes, apart from lime, are those supplying potassium, phosphorus and nitrogen. It is now recognised, however, that most of the other common elements occur in plants, though generally only in minute amounts, and that some of these minor constituents are essential to plants and to animals. Some may be present only fortuitously, but it is impossible to deny that they may have specific functions. Manganese and copper, for example, have been found in all plants investigated and are associated with rapidly growing parts, such as buds and leaves, and probably have a functional importance.

The small amounts of such elements in the soil are extracted by the roots of trees and transported to the growing parts, being eventually shed in the falling leaves, thus enriching the surface soil. This enrichment of the surface soil at the expense of the deeper soil by trees was clearly shown in the case of manganese by Bishop ${ }^{1}$, and further investigations of a similar nature are desirable. Maquenne and Demoussy ${ }^{2}$ examined the distribution of copper in a number of cultivated trees and shrubs and found the copper concentrated in the actively growing parts. Analyses of various parts of the native karaka tree have shown that the copper is concentrated in the leaves and seeds of this tree, and the same will probably be found in the case of other native trees. Copper is present normally only in minute amounts in the soil, but is gradually brought to the surface, like manganese, by tree growth. It is obvious that forests, besides building up a surface layer of humus, exercise the very important function of bringing to the surface various chemical elements extracted from the deeper soil. This process is cumulative and may extend over many hundreds of years.

In view of these considerations, it is possible to appreciate the damage that may be done by forest fires. Not infrequently the burning is sufficiently thorough to burn away the humus. On hilly ground the ash may be almost entirely washed away by rain, with the result that the beneficial umulative work of the forest carried on over vast periods may be destroyed in a day. Unless the ash and the humus can be retained, the work of the forest has been not only in vain, but even actually detrimental, in that the soil to the depth of the tree roots will have been impoverished in minor mineral constituents essential to healthy growth of plants and animals.

On flat land the floor of the forest is usually damp. Here there is less likelihood of complete destruction of humus by fire and of ashes being washed away either mechanically or in solution, except on very porous soil, but on hill and mountain-side the destructive effects of bush fires may be disastrous.

The comparative infertility of the gum lands north of Auckland is probably due very largely to the destruction of the forests and the surface soil of the hills by great fires. In the low-lying and swampy gum lands a layer of ashes, covered 
often by many feet of black peat, overlies the remains of a kauri forest. Frequently, at a lower level there is another layer of ashes above the roots of a still earlier kauri forest. The prehistoric fires that destroyed these forests doubtless destroyed the forests on the hilly ground, where kauri gum occurs very near the surface. The humus on the sloping ground was apparently destroyed and the ashes washed down into the sea. In recent years the scrub has been burnt off by gum diggers and others and further damage done to the fertility of the soil.

On very porous soil the mineral constituents of ash derived from forest fires may be washed down through the soil. Should there be a tendency towards any mineral deficiency in such soil, this deficiency may be greatly intensified by leaching. On soil of this nature it would appear desirable to grow deep-rooting crops to bring to the surface the small amounts of essential minerals, and to produce a retentive layer of humus. Much working, with consequent drainage and leaching of the surface soil, should be avoided.

It appears probable that humus may have mineral as well as biological importance and more analyses are desirable of its mineral content, particularly for those elements that occur only in minute amounts in underlying soil or rock. It is obvious that if the normal soil and rock is in any way deficient in minor mineral constituents essential to the full health of plants or animals, this deficiency will become serious if the humus in which such constituents have become concentrated is destroyed and the ashes removed.

${ }^{1}$ Australian J. Expt. Biol. Med. Sci., 5, $125 ; 1928$.

2. R. Acad. Sci., 170, 87; 1920.

\section{Canadian Water Power Development in 1932}

\section{By Dr. Brysson Cunningham}

$\mathrm{T}$ HE strides by which Canada continues to advance in the exploitation of the water power resources of the Dominion for the generation of electricity are as remarkable as the abundance of the resources themselves. According to a

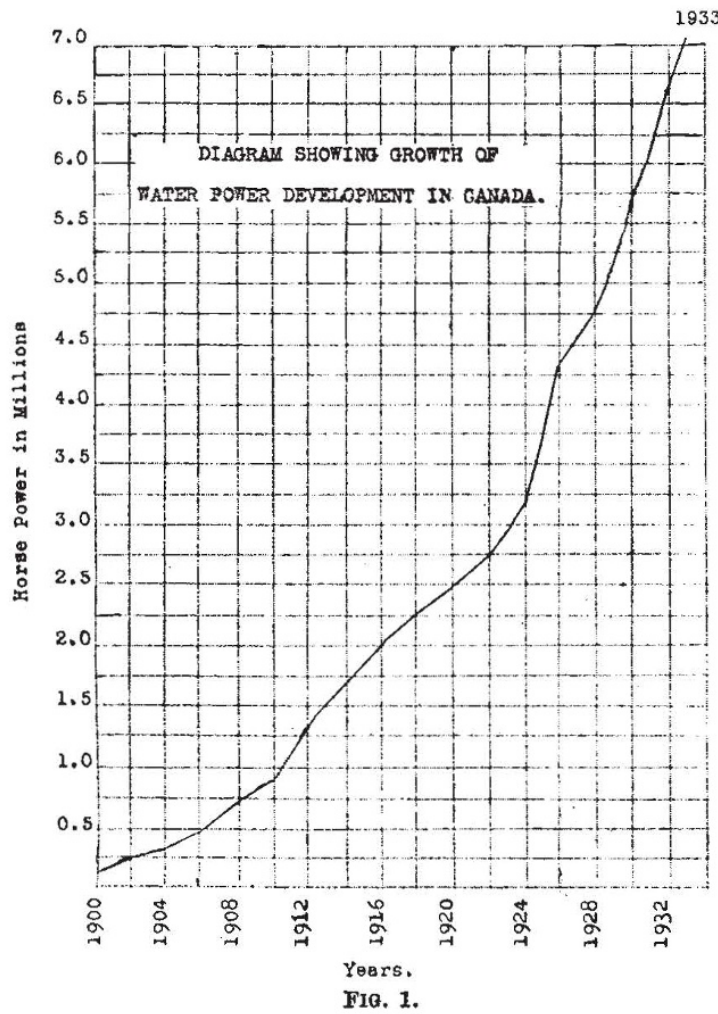

report $^{1}$ recently issued by the Water Power and Hydrometric Bureau of the Department of the Interior, the total turbine installation at the end of 1932 amounted to more than seven millions $(7,045,260)$ horse power, showing an increase of 378,923 horse power over the corresponding figure for the previous year. This gives an average of 670 horse power per 1,000 of population, a ratio which places Canada in an outstanding position among the water power-using countries of the world.

The remarkable character of the progress which has been made since the commencement of the present century will be best appreciated by a glance at the graph in Fig. 1, reproduced from the report. In 1900 , the quantity of power realised was less than a quarter of a million horse power: it was still less than a million ten years later. By 1920, however, it had reached $2 \frac{1}{2}$ millions, and in $1930,5 \frac{3}{4}$ millions. Between 1928 and 1930, progress was at the rate of half a million horse power per annum, and practically the same rate prevailed up to the beginning of 1932. Last year, there was a slight falling off, but this does not necessarily imply any relaxation of effort, since the additional power is only recorded on completion of the particular undertaking from which it emanates, and anything from two to five years may be required for the execution of individual projects. Various schemes are at present under way, most of which had their inception three or four years ago, before the general suspension, or retardation, of industrial expansion, due to the world-wide financial depression set in. In common with the experience of nearly all countries, there has been of late years a definite decrease in the demand for power, which reached its greatest intensity in the middle of 1931. A recent statement ${ }^{2}$ of the Minister of the Interior, the Hon. Thos. G. Murphy, gives, however, a hopeful impression. "More stable conditions," he says, "now appear to have been established, since the figures for the first ten months of 1932 indicate that electric energy produced for use in Canada is practically the same as for the corresponding period in 1931-an encouraging feature being that in August, September and October, the last three 